\title{
CORRESPONDENCE
}

\section{T-regulatory cells in COPD or tumour environment}

\section{To the Editors:}

We read with great interest the paper by ISAJEvs et al. [1] published recently in the European Respiratory Journal. The role of regulatory cells in the pathomechanism of chronic obstructive pulmonary disease (COPD) is an interesting issue and has been the subject of our studies on the systemic effects in COPD. Our results suggest that in COPD patients, the proportion of T-regulatory cells (identified by flow cytometry with CD4/ CD25/ CTLA4 antibodies) is significantly decreased [2]; thus, the attention captured by the aforementioned article. It seems to us that there are some aspects which need to be clarified by the authors.

The authors investigated T-regulatory cells in the lung environment. The aim of the study was to analyse the role of these cells in the pathogenesis of COPD; however, the lung tissue specimens came mainly from patients with nonsmall cell lung cancer (NSCLC). We were not able to find any detailed clinical data on the neoplastic disease, especially its stage. The histological type of NSCLC is also of great importance. The authors, of course, are aware of this study limitation but deal with this problem superficially in their discussion. They state that the specimens were taken "as far as possible" from the tumour site; this needs to be defined more precisely. A malignant process within the lung triggers significant immunological disturbances [3]. The immunological response in the early stage of the disease differs from that in the later stages, particularly when the cancer begins to be symptomatic. This usually happens when mechanisms of aggression predominate and host defense is significantly disturbed. At this stage, changes in the immunological system affect not only the lung involved but also spread to the whole respiratory system and may even be systemic [3]. The degree of the impairment of antitumour defense correlates with tumour stage. The role of T-regulatory cells in inhibiting cytotoxic antitumour immunity has been documented $[4,5]$. An increased proportion of these cells has been observed in the environment of lung cancer and mesothelioma [6]. We also found an increased proportion of these cells in BALF from lung cancer patients: the mean proportion of CD4+/CD25+ in the CD4+ population was $47 \%$ in cancer patients and was higher than that in patients with interstitial lung disease (14\%) [7]. Therefore, the results of ISAJEVIS et al. [1] who found that FOX3 positive cells are upregulated in large airways and downregulated in the small airways could be affected by tumour stage and location.

Furthermore, we would advise caution in the interpretation of pulmonary function tests in these patients. It is difficult to determine if airway obstruction is caused by COPD or lung cancer itself, as airflow limitation may be seen in central lung tumours. The authors examined a large lung tissue sample; therefore, it was possible to verify the presence of emphysema in the specimens. The description of the emphysematous changes would certainly contribute to the value of the study and increase the credibility of COPD diagnosis.

Another point which needs to be highlighted is the number of nonsmokers in the control group. They accounted for $32 \%$ in the group of patients with lung cancer, a proportion rarely seen in other studies. Were they actually nonsmokers or perhaps ex-smokers? In our opinion, this issue needs to be elucidated.

The immunological changes in smokers, patients with lung cancer and patients with COPD have been the subject of our interest for many years. That is why it seems to us that conclusions from the results obtained in such a study group may be misleading. Perhaps presenting more clinical data regarding the lung tumours could help clear the doubts and increase the value of this interesting paper. Another solution might be referring the results and conclusions to lung cancer and not COPD.

\section{J. Domagala-Kulawik and M. Maskey-Warzecowska}

Dept of Pneumonology and Allergology, Warsaw Medical University, Warsaw, Poland.

Correspondence: J. Domagala-Kulawik, Dept of Pneumonology and Allergology, Warsaw Medical University, ul. Banacha 1a, 02 097 Warsaw, Poland. E-mail: domagalakulawik@gmail.com

Statement of Interest: None declared.

\section{REFERENCES}

1 Isajevs S, Taivans I, Strazda G, et al. Decreased FOXP3 expression in small airways of smokers with COPD. Eur Respir J 2009; 33: 61-67.

2 Fijalkowski R, Domagala-Kulawik J, Dabrowska M, et al. Regulatory cells in COPD patients. Preliminary report. ERS Annual Congress 2008; E4244. www.ers-education.org/lr/abstract.aspx?idMedia $=77930$.

3 Domagała- Kulawik J, Hoser G, Droszcz P, Kawiak J, Droszcz W, Chazan R. T cell subtypes in the bronchoalveolar lavage fluid and in the peripheral blood from patients with primary lung cancer. Diagnostic Cytopathol 2001; 4: 208-213.

4 Gallimore A, Godkin A. Regulatory T cells and tumour immunity observations in mice and men. Immunology 2008; 123: 157-163.

5 Baecher-Allan C, Anderson DE. Regulatory cells and human cancer. Semin Cancer Biol 2006; 16: 98-105.

6 Petersen RP, Campa MJ, Sperlazza J, Conlon D, Joshi MB, Harpole DH Jr, Patz EF Jr. Tumor Infiltrating Foxp3+ Regulatory T-Cells Are Associated With Recurrence in Pathologic Stage I NSCLC Patients. Cancer 2006; 107: 2866-2872.

7 Domagala-Kulawik J, Kawiak J, Hoser G, et al. Regulatory T cells in lung diseases - preliminary report. ERS Annual Congress 2007; E4486. www.ers-education.org/lr/abstract.aspx?idMedia $=5704$. 